\title{
Multichromophoric sugar for fluorescence photoswitching
}

\author{
Stéphane Maisonneuve ${ }^{1}$, Rémi Métivier ${ }^{*}{ }^{1}$, Pei $\mathrm{Yu}^{2}$, Keitaro Nakatani ${ }^{1}$ \\ and Juan Xie ${ }^{* 1}$
}

\section{Full Research Paper}

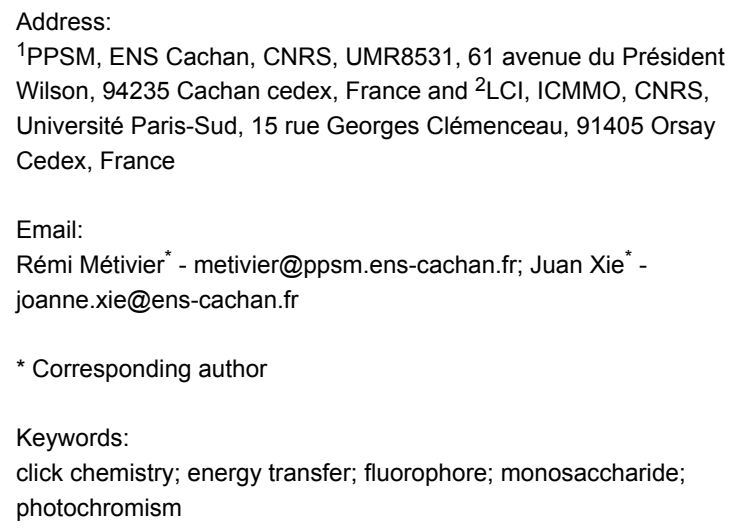

\author{
Beilstein J. Org. Chem. 2014, 10, 1471-1481. \\ doi:10.3762/bjoc. 10.151 \\ Received: 07 March 2014 \\ Accepted: 28 May 2014 \\ Published: 30 June 2014 \\ This article is part of the Thematic Series "Multivalent glycosystems for \\ nanoscience". \\ Guest Editor: J.-L. Reymond
}

(C) 2014 Maisonneuve et al; licensee Beilstein-Institut. License and terms: see end of document.

\begin{abstract}
A multichromophoric glucopyranoside $\mathbf{2}$ bearing three dicyanomethylenepyran (DCM) fluorophores and one diarylethene (DAE) photochrome has been prepared by $\mathrm{Cu}(\mathrm{I})$-catalyzed alkyne-azide cycloaddition reaction. The fluorescence of 2 was switched off upon UV irradiation, in proportion with the open to closed form (OF to CF) conversion extent of the DAE moiety. A nearly $100 \%$ Förster-type resonance energy transfer (FRET) from all three DCM moieties to a single DAE (in its CF) moiety was achieved. Upon visible irradiation, the initial fluorescence intensity was recovered. The observed photoswiching is reversible, with excellent photo resistance.
\end{abstract}

\section{Introduction}

The development of functional nanomaterials is nowadays a very attractive field of fundamental and applied research. The chemical functions at the molecular level yield properties, which are translated in terms of specific electronic or optical functions to the materials and device level. One of the challenges is to synthesize organic nano-architectures with a high degree of structural order and well-defined properties yielding high-performance functions, for both economic and environmental saving reasons. Saccharides are polyfunctional molecules with well-defined stereogenic centres in one molecular

unit, and constitute "platforms" on which multiple functional moieties can be attached. Among many applications, the use of photochemical devices based on sugar derivatives is particularly appealing for the development of supramolecular systems for optical data storage media. Photochromic molecules are particularly efficient photo-driven switches, as they can commute upon light excitation between two distinct molecular species (states A and B, Figure 1) with the possibility to cycle up to one million "round trips", showing different physical and chemical properties, the most noticeable one being the absorp- 


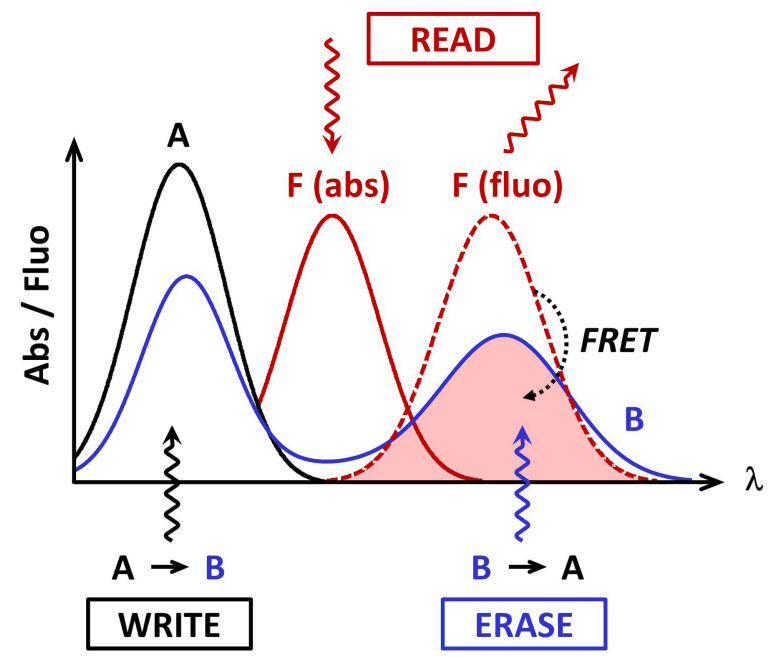

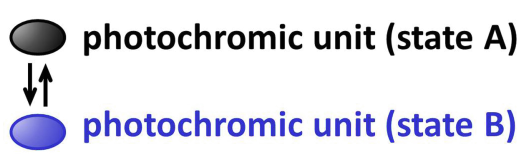

fluorescent unit (F)

(- absorption / --- fluorescence)

quenching process by directional
energy transfer (FRET)

Figure 1: Requirements on absorption and emission spectral features of the photochromic and fluorescent units of the platform to induce efficient fluorescence photoswitching by energy transfer process (FRET).

tion change [1]. Indeed, they usually shuttle between a colorless and a colored form. Combining them with fluorescent compounds provides an added value to their photophysical function. Actually, fluorescence allows the possibility to reach high sensitivity and very low detection levels, down to the single molecule limit, whereas absorption spectroscopy requires a high number of active molecules [2]. If structural and spectral features of the fluorophore and the photochromic compound fit well together, the fluorescence can be switched ON and OFF: quenching of the fluorescence through a Förster-type resonance energy transfer (FRET) process from the former to the latter would occur, when the photochromic moiety is in the colored form (state B, Figure 1). At the opposite, in the colorless form (state A), the absence of FRET would keep the fluorescence alive, showing that the combination of these two functional molecules leads to a photon-driven fluorescence switch.

Previously, we have synthesized a fluorescent-photochromic dyad (1, Figure 2) combining a DCM fluorophore (4-dicyanomethylene-2-tert-butyl-6-( $p$-dialkylaminostyryl)- $4 \mathrm{H}$ -

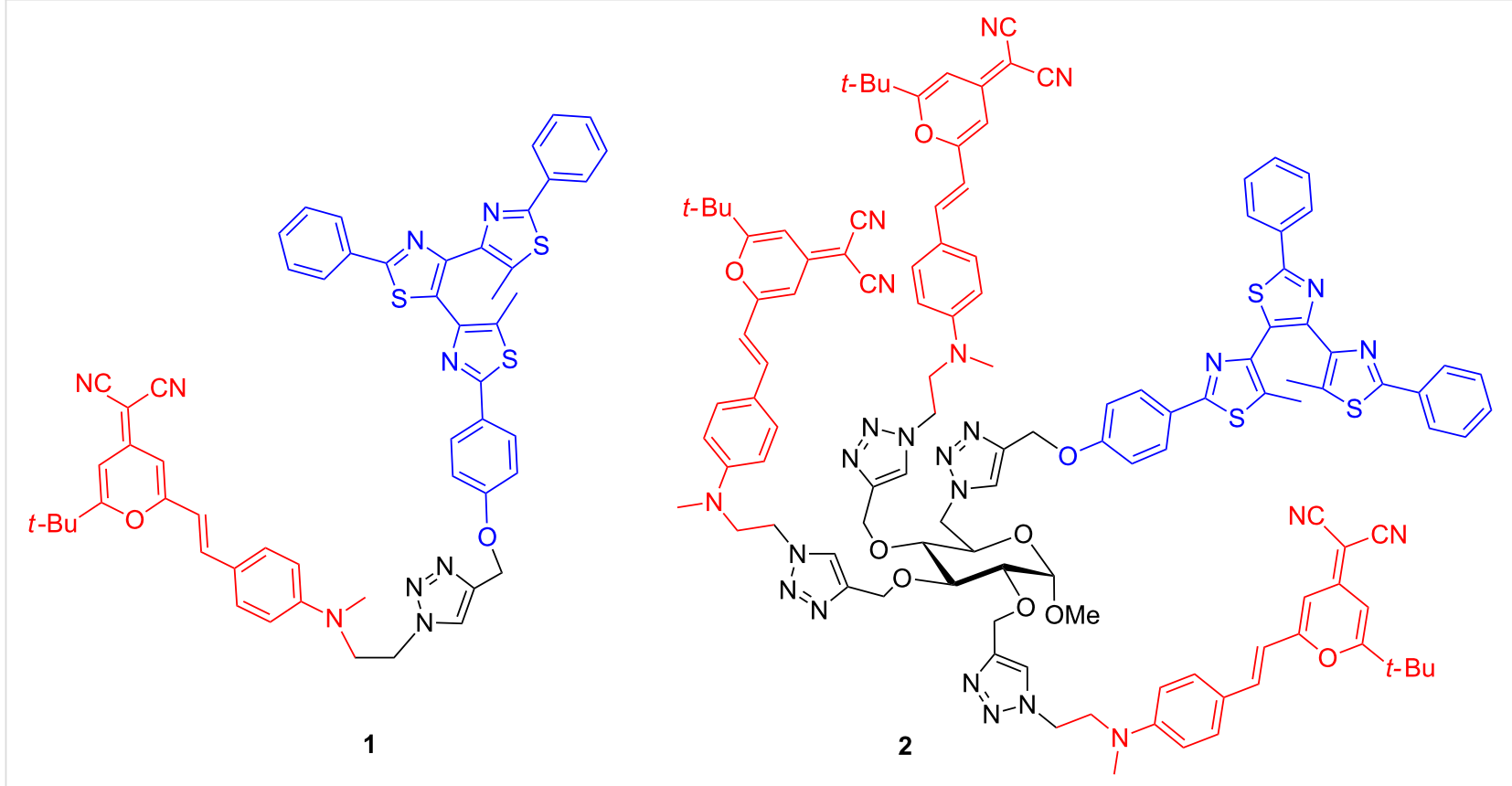

Figure 2: Bifunctional fluorescent-photochromic molecules 1 and 2. 
pyran) [3] with a photochromic diarylethene (DAE) which showed a photoreversible two-way FRET controlled by the state of the photochromic moiety, and $49 \%$ quenching of the fluorescence upon UV irradiation [4]. Bifunctional molecules built on two distinct (photochrome and fluorophore) moieties have also been reported by other groups [5-9]. The fluorophore vs photochrome ratio in reported bifunctional systems is 1:1 [4-7] or 2:1 [8,9]. Other strategies to assemble interacting fluorophores and photochromes (supramolecular systems, nanoparticles, polymer materials) are also reported [10-13]. FRET operates at distances of a few nanometers around the photochromic moiety (in its state B, Figure 1), which is related to the Förster radius. It means that in a suitably designed molecular system, one single photochromic unit can quench several fluorophores present within this distance. In a situation where one photochromic unit is surrounded by several fluorophores, we can take advantage of this phenomenon both to increase the brightness of the fluorescent molecular system and to turn "ON" and "OFF" several fluorophores with one given photochromic molecule. This is valuable in terms of photon (thus energy) saving, since "switching a few photochromes leads to quenching many fluorophores". In this perspective, we decided to design a multichromophoric glycopyranoside bearing three DCM fluorophores and one photochromic bis(dithiazole)ethane [14-16] (compound 2, Figure 2) so as to take advantage of this sugarbased "platform" to get a specific molecular architecture and to study the energy transfer and photo-switching efficiency. To the best of our knowledge, readily available monosaccharides have been rarely used to develop multichromophoric supramolecular systems. Only one artificial light-harvesting antenna system grafted on the $\alpha$-D-glucopyranoside has been reported [17].

\section{Results and Discussion \\ Synthesis of multichromophoric sugars}

Synthesis of organic nano-architectures with a high degree of structural order and defined properties is challenging because sophisticated multistep experimental procedures are often implicated. Recently, the $\mathrm{Cu}(\mathrm{I})$-catalyzed alkyne-azide cycloaddition reaction ( $\mathrm{CuAAC}$, an excellent example of click chemistry) has been demonstrated as a robust and highly efficient ligation tool to conjugate various azido- and alkyne-functionalized moieties [18-20]. Monosaccharides can be readily functionalized with several propargyl groups to synthesize, using click chemistry, multivalent neoglycoconjugates for recognition studies with carbohydrate-binding proteins (lectins) [21-24] or to develop light-harvesting antenna systems [17]. In order to introduce three DCM fluorophores and one photochromic species into the glycopyranoside scaffold, methyl 6- $O$-trityl- $\alpha$ D-glucopyranoside 3 was chosen as starting material (Scheme 1). $O$-Propargylation followed by microwave-assisted CuAAC with azido-functionalized DCM fluorophore 5 [25] in the presence of copper sulfate and sodium ascorbate led to the fluorescent glucoside 6 . The trityl group was then removed by a catalytic amount of acetyl chloride in a mixture of $\mathrm{MeOH}$ and $\mathrm{CH}_{2} \mathrm{Cl}_{2}$. Subsequent activation as mesylated followed by "microwave-assisted" nucleophilic substitution with sodium azide afforded the corresponding 6-azido sugar 8 which was treated with alkyne-functionalized photochromic diarylethene 9 [26] to furnish the target compound $\mathbf{2}$ in $68 \%$ yield. The structure of this compound has been confirmed by NMR and HRMS spectra.

\section{Photophysical studies}

The fluorescent glucoside derivative $\mathbf{6}$, bearing three DCM fluorophores, is used as a model fluorescent compound. Its absorption spectrum in acetonitrile, plotted in Figure 3a, shows a main large band peaking at $455 \mathrm{~nm}$. It exhibits a wide fluorescence spectrum between $550 \mathrm{~nm}$ and $700 \mathrm{~nm}$, with a maximum located at $610 \mathrm{~nm}$ (Figure 3b), associated with a fluorescence quantum yield $\Phi_{\mathrm{F}}=0.12$. These spectroscopic characteristics are rather comparable to the absorption and fluorescence features of the fluorophore 5 [4]. The photophysical properties of the photochromic model compound 9 have been described in a previous report [4]. Briefly, the diarylethene 9 is originally in its colorless open form (9-OF), with an absorption spectrum in acetonitrile located in the UV range $\left(\lambda_{\max }=317 \mathrm{~nm}\right.$, Figure $3 \mathrm{c}$, full black line). In this state, 9-OF is moderately fluorescent in the blue region $\left(\lambda_{\max }=440 \mathrm{~nm}, \Phi_{\mathrm{F}}=0.016\right.$, Figure $\left.3 \mathrm{~d}\right)$. Under irradiation at $335 \mathrm{~nm}, 9-\mathrm{OF}$ undergoes a cyclisation photoreaction yielding the molecule in its colored and non-fluorescent closed form (9-CF), as revealed by the appearance of a large absorption band peaking in the 500-700 $\mathrm{nm}$ range (Figure 3c, full blue line). The photostationary state (PSS) reached under $335 \mathrm{~nm}$ illumination is composed of $91 \%$ of 9 -CF and $9 \%$ of 9-OF (Figure 3c, dashed line). The target compound 2 can be considered as the assembly of the fluorescent model derivative $\mathbf{6}$ and the photochromic model compound 9. Indeed, before any UV irradiation, the absorption spectrum of $\mathbf{2}$ in its open form (2-OF) represents the overlay of the absorption feature of $\mathbf{6}$ and 9-OF: as displayed in Figure 3e (full line), the absorption band at $455 \mathrm{~nm}$ matches to the three fluorophores, whereas the absorption bands at $286 \mathrm{~nm}$ and $325 \mathrm{~nm}$ correspond mostly to the photochromic diarylethene moiety. The fluorescence spectrum of 2-OF shows a very weak blue emission band between $400 \mathrm{~nm}$ and $500 \mathrm{~nm}$ from the diarylethene unit, and a rather strong red emission band peaking at $610 \mathrm{~nm}$ from the three DCM dyes (Figure 3f). This dual emission will be discussed further, by a careful analysis of excitation spectra (vide infra). Figure $4 \mathrm{a}$ and $\mathrm{b}$ show that upon increasing irradiation times at $335 \mathrm{~nm}$, an absorption band at $600 \mathrm{~nm}$ emerges, corresponding to the photochromic moiety in its thermally stable closed form, and the fluorescence emission is concomitantly quenched by 

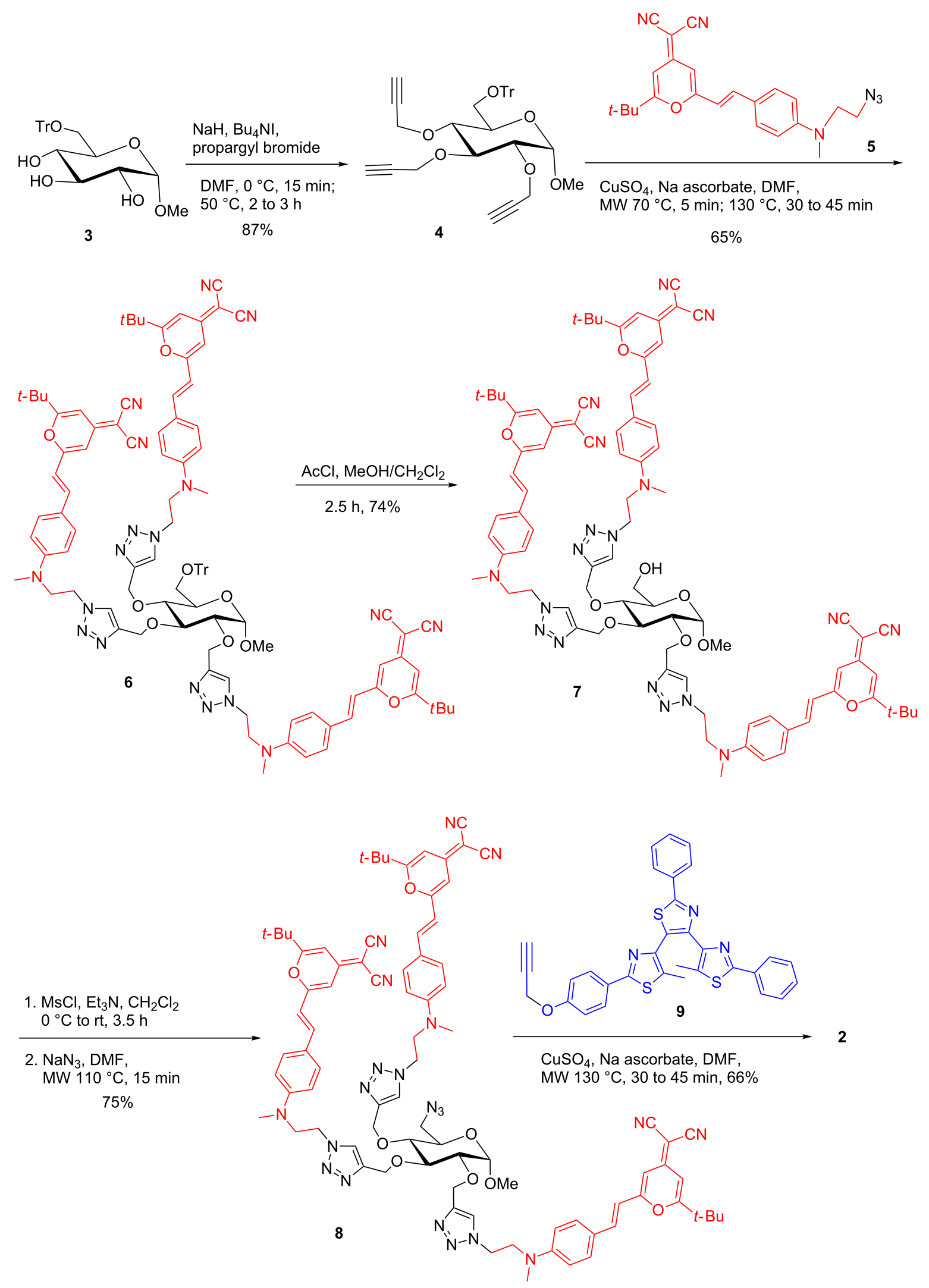

Scheme 1: Synthesis of multichromophoric glucopyranoside 2. 


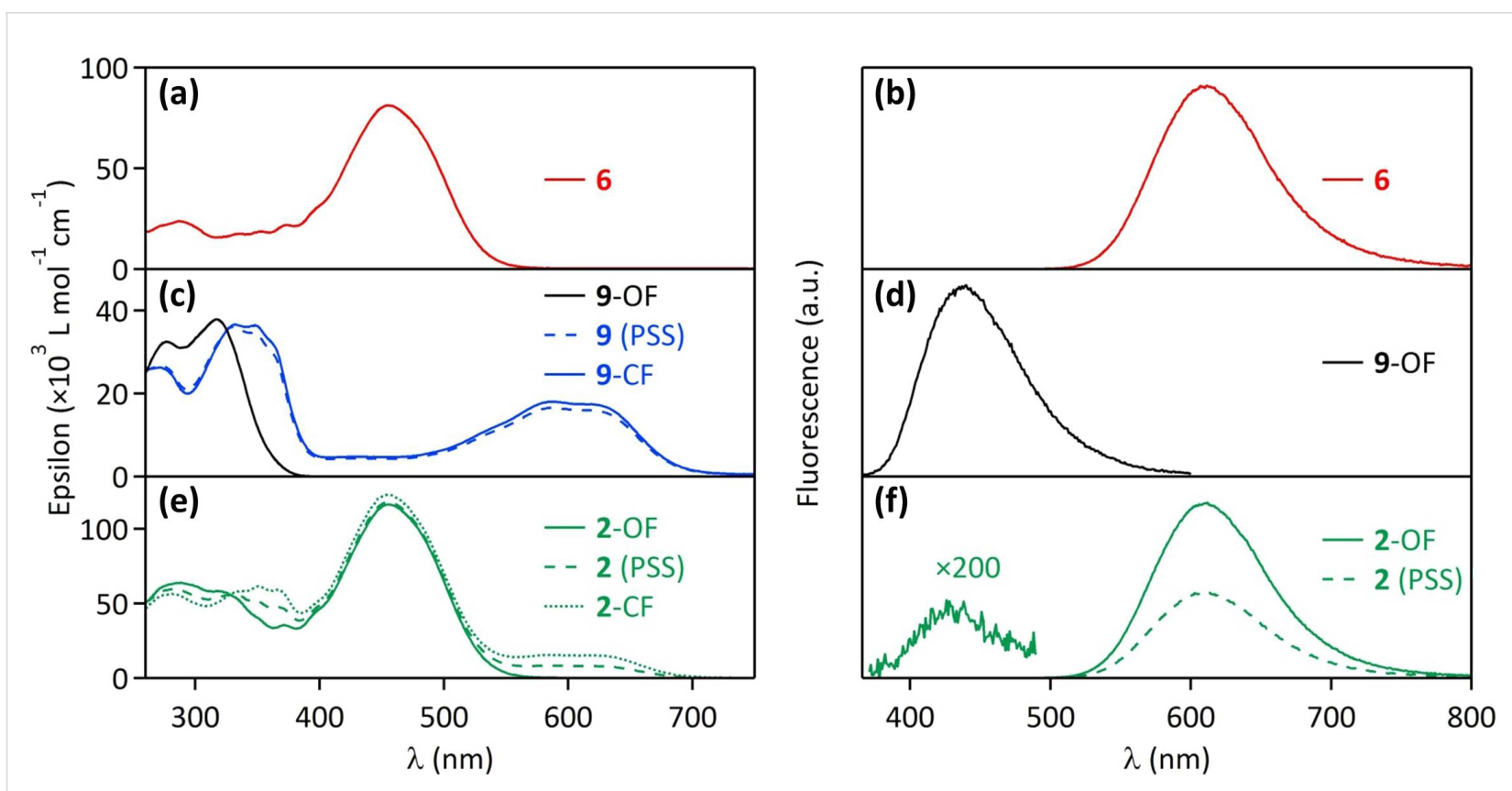

Figure 3: Absorption and fluorescence spectra of compounds 6, 9, and 2 in $\mathrm{CH}_{3} \mathrm{CN}$ : (a) absorption spectrum of $\mathbf{6}$; (b) emission spectrum of $\mathbf{6}$ $\left(\lambda_{\text {exc }}=450 \mathrm{~nm}\right)$; (c) absorption spectra of $\mathbf{9 - O F}, 9$ at the photostationary state (PSS) under $335 \mathrm{~nm}$ illumination, isolated $\mathbf{9 - C F}$; (d) emission spectrum of 9-OF $\left(\lambda_{\text {exc }}=325 \mathrm{~nm}\right.$ ); (e) absorption spectra of 2-OF, 2 at the photostationary state (PSS) under 335 nm illumination (no noticeable change has been observed over 5 days, indicating the thermal stability of 2), 2-CF (obtained by extrapolation of the ${ }^{1} \mathrm{H}$ NMR vs UV-visible absorption experiment, see text for details); (f) emission spectra of $2-\mathrm{OF}$ and $\mathbf{2}$ at the photostationary state (PSS) under $335 \mathrm{~nm}$ illumination $\left(\lambda_{\mathrm{exc}}=325 \mathrm{~nm}\right)$.

$51 \%$. As displayed in Figure 3, the emission band of the fluorophores in the 550-700 $\mathrm{nm}$ range overlaps well the absorption band of the photochromic derivative in its closed form, in the same spectral region. Therefore, the fluorescence quenching observed for the compound $\mathbf{2}$ under UV irradiation can be easily interpreted as the consequence of a FRET process from the DCM fluorophores (donors) to the diarylethene derivative in its colored closed form (acceptor), which plays the role of the quencher. The multichromophoric system $\mathbf{2}$ is completely reversible: under irradiation at $575 \mathrm{~nm}$, the cycloreversion reaction 2-CF $\rightarrow$ 2-OF occurs, the absorption band centered at $610 \mathrm{~nm}$ drops back to zero and the fluorescence of the sample is fully recovered (Figure $4 \mathrm{c}$ and d). As shown in Figure 4e and f, several UV-visible irradiation cycles were applied to the system without any degradation of its photophysical properties, revealing its excellent fatigue resistance.

${ }^{1} \mathrm{H}$ NMR spectra were recorded under increasing irradiation times at $335 \mathrm{~nm}$ in order to follow the photoisomerisation of compound 2 (Figure 5), and corresponding UV-visible absorption spectra were measured, in order to correlate the absorption changes with the $\mathrm{OF} \rightarrow \mathrm{CF}$ conversion yield. Under $335 \mathrm{~nm}$ illumination, new signals appear near $5.2 \mathrm{ppm}$ (for $\mathrm{OCH}_{2}$ group) and 6.5 to $8.0 \mathrm{ppm}$ which are induced by the photocyclisation of the photochromic moiety from the open to the closed form. Due to higher concentration of NMR sample, the maximum conversion reached was about $39 \%$. Such combined ${ }^{1} \mathrm{H}$ NMR vs UV-visible absorption data allowed us to extrapolate the absorption spectrum of the dyad molecule in its pure closed form 2-CF, as plotted in Figure $3 \mathrm{e}$ (dotted line). It appears that the PSS obtained for the compound $\mathbf{2}$ with a lightirradiation at $335 \mathrm{~nm}$ corresponds to a mixture of $53 \%$ of $2-\mathrm{CF}$ and $47 \%$ of 2 -OF. Such a conversion yield has to be compared to the fluorescence quenching of $\mathbf{2}$ observed after irradiation at $335 \mathrm{~nm}$ (51\% fluorescence quenching, vide supra). Therefore, the incomplete fluorescence quenching is due to a limited photochromic conversion yield under UV light. Furthermore, since the photochromic conversion yield (53\%) corresponds almost to the fluorescence quenching (51\%), the FRET process appears to be extremely efficient: under irradiation at $335 \mathrm{~nm}$, half of the multichromophoric system is still in its initial open form 2-OF, associated with a strong fluorescence emission, and another half are promoted in their closed form 2-CF, whose fluorescence is almost totally quenched by FRET.

This phenomenon is well-supported by time-resolved fluorescence measurements. Fluorescence decay curves of 6, 2-OF, and $\mathbf{2}$ after irradiation at $335 \mathrm{~nm}$ were recorded in acetonitrile by the time-correlated single photon counting method (TCSPC) at $\lambda_{\text {exc }}=475 \mathrm{~nm}$, and analyzed by a sum of three exponential components (Table 1). The model fluorescent glucoside derivative 6 shows a main time-constant at $\tau_{1}=1.00 \mathrm{~ns}$, a second 

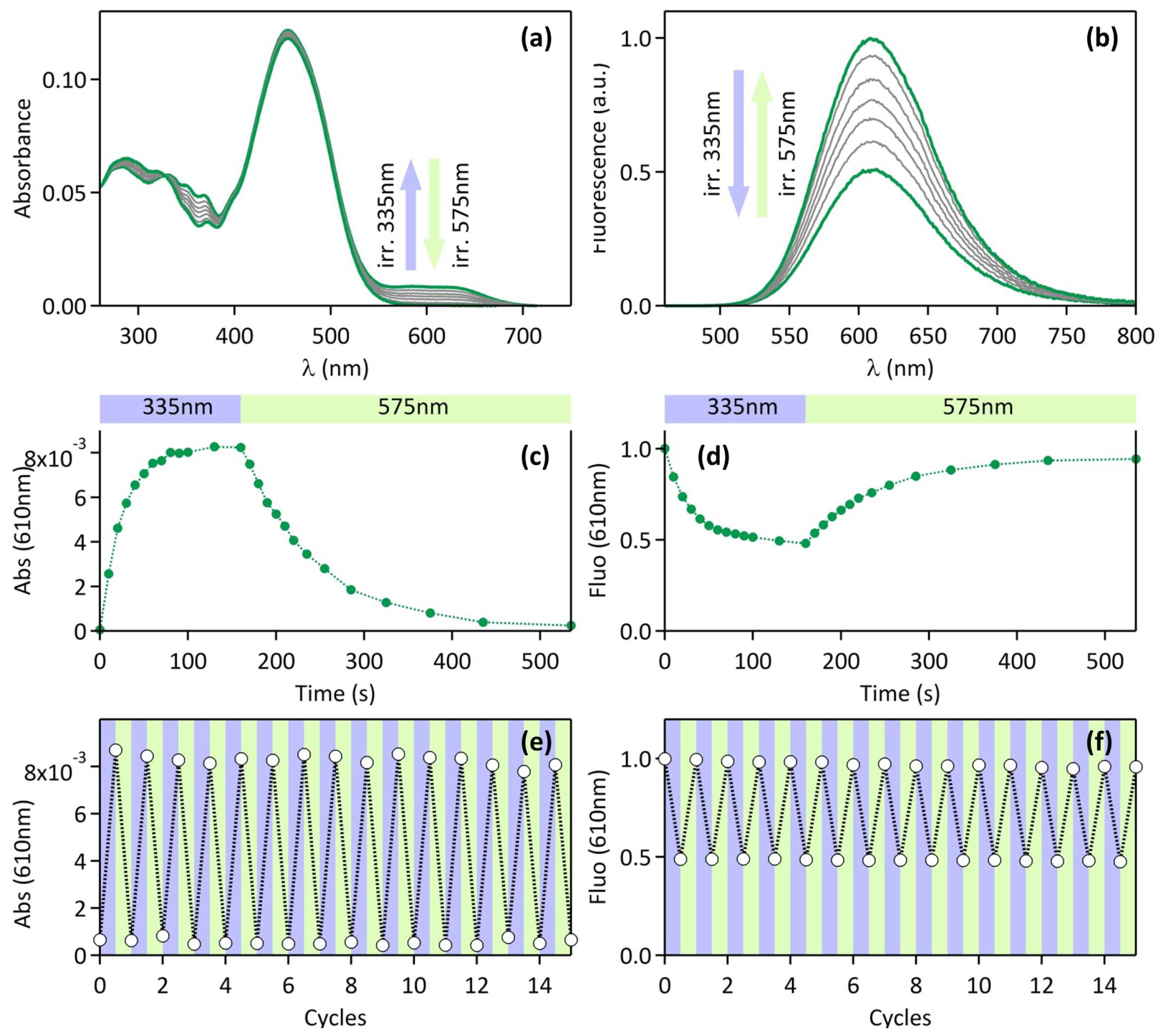

Figure 4: Absorption and fluorescence changes of compound $2\left(1.0 \mu \mathrm{M}\right.$ in $\left.\mathrm{CH}_{3} \mathrm{CN}\right)$ upon UV-visible irradiation: (a) absorption and (b) emission spectra $\left(\lambda_{\text {exc }}=450 \mathrm{~nm}\right)$ under increasing irradiation times at $335 \mathrm{~nm}$; (c) time-evolution profile of absorption and (d) emission upon irradiation at $335 \mathrm{~nm}$ and $575 \mathrm{~nm}$; (e) fatigue resistance followed by the absorption band at $610 \mathrm{~nm}$ and (f) the emission band at $610 \mathrm{~nm}$ under alternate $355 \mathrm{~nm} /$ $575 \mathrm{~nm}$ irradiation cycles. Irradiation conditions at $335 \mathrm{~nm}$ : (a-d) $2.7 \mathrm{~mW} \mathrm{~cm}^{-2}$ and (e,f) $40 \mathrm{~s}$ at $7.2 \mathrm{~mW} \mathrm{~cm}^{-2}$. Irradiation conditions at $575 \mathrm{~nm}$ : (a-d) $3.1 \mathrm{~mW} \mathrm{~cm}^{-2}$ and (e,f) $120 \mathrm{~s}$ at $9.5 \mathrm{~mW} \mathrm{~cm}^{-2}$.

component at $\tau_{2}=0.35 \mathrm{~ns}$, and a minor time-constant at $\tau_{3}=0.04 \mathrm{~ns}$. The latter one has been neglected in the following discussion, since it is very close to the time-resolution of our instrument, and associated with a very low fraction of intensity (0.02). The two other time-constants are attributed to the $E$-isomer $\left(\tau_{1}\right)$ and the $Z$-isomer $\left(\tau_{2}\right)$ of the fluorophores, which is consistent with our previous studies [4]. The fluorescence decays of 2-OF and $\mathbf{2}$ after irradiation at $335 \mathrm{~nm}$ are plotted in Figure 6a, and the result of a global three-exponential fitting procedure is displayed on Table 1. The three time-constants obtained by this method are in the same range as the ones determined for 6: $\tau_{1}=1.26 \mathrm{~ns}, \tau_{2}=0.47 \mathrm{~ns}, \tau_{3}=0.05 \mathrm{~ns}$, associated with the fraction of the intensities comparable to 6 . In a similar manner, the two significant contributions correspond to the $E$ and $Z$-isomers of the fluorophores, respectively. Interestingly, the fluorescence decay curves of $\mathbf{2}$ before and after UV irradiation are overlapping, and the results of the fitting are identical in both cases, despite the fact that the fluorescence intensity is decreased by a factor of two (51\% fluorescence quenching, vide supra). Such an observation is compatible with a static FRET quenching process. Indeed, when the PSS is reached under $335 \mathrm{~nm}$ irradiation, the population of 2-OF molecules represents $47 \%$ of the whole system, behaves as the initial non-irradiated molecules and contributes to the fluorescence decay, 


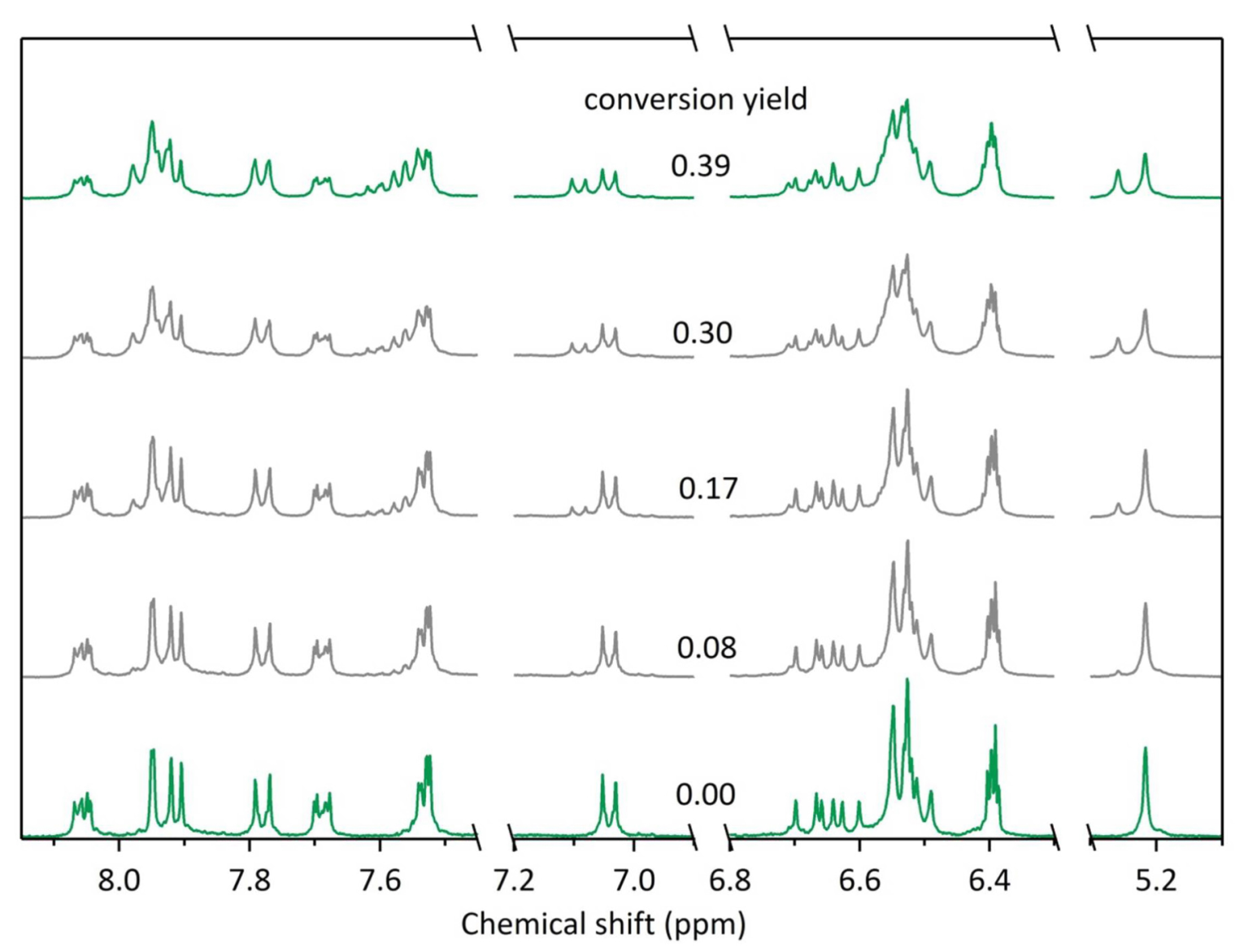

Figure 5: Partial ${ }^{1} \mathrm{H}$ NMR spectra of compound $2\left(11 \mu \mathrm{M}\right.$ in $\left.\mathrm{CD}_{3} \mathrm{CN} / \mathrm{DMSO}-\mathrm{d}_{6} 4: 1\right)$ before and after increasing irradiation times at $335 \mathrm{~nm}$ (from bottom to top). The conversion yield at each irradiation time is deduced from the integration of signals around 5.2-5.3 and 7.0-7.1 ppm.

\begin{tabular}{|c|c|c|c|c|}
\hline & $\mathrm{T}_{1} / \mathrm{ns}\left(a_{1}, f_{1} \mathrm{a}^{\mathrm{a}}\right)$ & $\mathrm{T}_{2} / \mathrm{ns}\left(a_{2}, f_{2}{ }^{\mathrm{a}}\right)$ & $\mathrm{T}_{3} / \mathrm{ns}\left(a_{3}, f_{3}{ }^{\mathrm{a}}\right)$ & $\mathrm{X}^{2} R$ \\
\hline 6 & $1.00(0.43,0.79)$ & $0.35(0.29,0.19)$ & $0.04(0.28,0.02)$ & 1.08 \\
\hline $2-\mathrm{OF}^{\mathrm{b}}$ & $1.26(0.40,0.75)$ & $0.47(0.33,0.23)$ & $0.05(0.27,0.02)$ & 1.16 \\
\hline 2 (PSS under irradiation at $335 \mathrm{~nm}$ ) & $1.26(0.35,0.74)$ & $0.47(0.30,0.23)$ & $0.05(0.35,0.03)$ & 1.12 \\
\hline
\end{tabular}

aThe fraction of intensities $f_{i}$ is defined as follows: $f_{\mathrm{i}}=a_{\mathrm{i}} \mathrm{T}_{\mathrm{i}} / \Sigma a_{\mathrm{j}} \mathrm{T}_{\mathrm{j}}$. ${ }^{\mathrm{b}}$ Results obtained by means of a global fitting procedure.

whereas the population of $\mathbf{2}$-CF molecules (53\% of the system) is fully quenched through a very efficient FRET process, its contribution to the emission signal is negligible, and its decaytime is obviously below the time-resolution of our instrument. As a conclusion, the FRET process from the fluorophores to the closed form of the photochromic diarylethene is close to $100 \%$ in the molecule 2 .

Fluorescence excitation spectra provide another evidence of FRET intramolecular phenomenon within the compound 2. Indeed, the excitation spectrum of the model fluorescent glucoside 6, displayed in Figure $6 \mathrm{~b}$ (red curve), resembles to the shape of its absorption spectrum, with a large band centered at $455 \mathrm{~nm}$. However, the excitation spectrum of the molecule 2-OF recorded at $\lambda_{\mathrm{em}}=620 \mathrm{~nm}$ (corresponding to the fluorophore emission) shows an additional contribution in the 250-350 nm range, which corresponds to the open form of the photochromic moiety, revealing a FRET process from the open form of the diarylethene unit (donor) to the DCM fluorophores (acceptors). This energy transfer pathway is actually allowed by the favorable spectral overlap in the $400-500 \mathrm{~nm}$ range between the blue emission of the photochromic moiety in its open form (see Figure 3d) and the absorption of the fluorophores (see Figure 3a). As evidenced previously on 1 [4], this "reverse" 

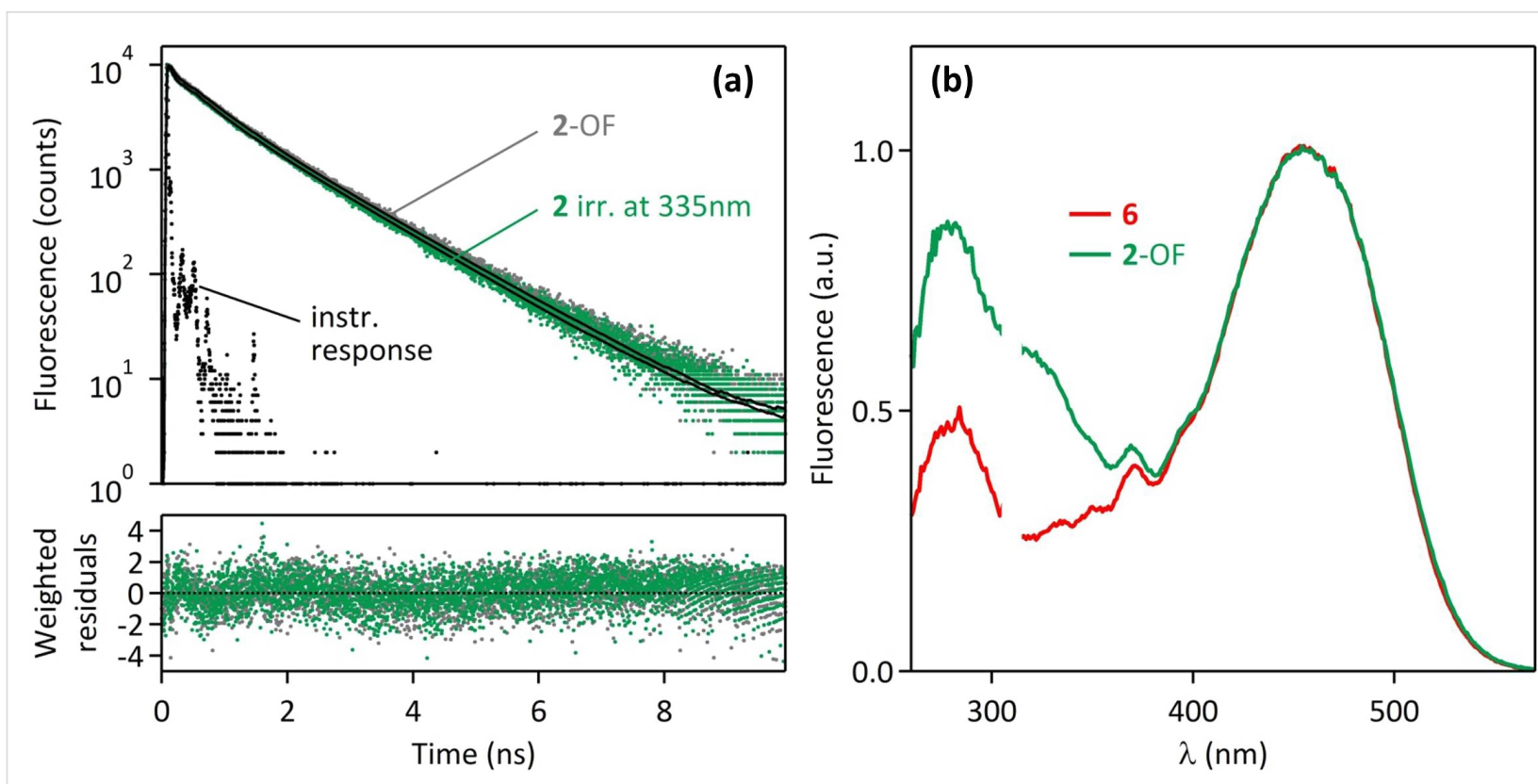

Figure 6: (a) Fluorescence decays $\left(\lambda_{\mathrm{exc}}=475 \mathrm{~nm}, \lambda_{\mathrm{em}}=610 \mathrm{~nm}\right)$ of compound 2-OF, and 2 after irradiation at $335 \mathrm{~nm}$ in $\mathrm{CH}_{3} \mathrm{CN}\left(7 \mathrm{~mW} \mathrm{~cm}^{-2}\right)$. (b) Normalized excitation spectra $\left(\lambda_{\mathrm{em}}=620 \mathrm{~nm}\right.$ ) of 6 (red line) and 2-OF (green line) in $\mathrm{CH}_{3} \mathrm{CN}$.

FRET explains why the emission of the photochromic moiety is almost absent in the fluorescence spectrum of the dyad 2-OF (Figure 3f).

Finally, the limited conversion yield of the molecule 2 under irradiation in the UV (53\%), compared to the model photochromic compound 9 (conversion yield $=91 \%$ ) can be explained by this efficient double FRET effect: (i) the energy transfer from the open form of the photochromic unit to the fluorophores tends to deactivate the photochromic activity of 2-OF, and (ii) the energy transfer from the fluorophores to the closed form of the photochromic unit contributes to favor the $\mathrm{CF} \rightarrow$ OF cycloreversion reaction. Consequently, the PSS of $\mathbf{2}$ when irradiated at $335 \mathrm{~nm}$ is much lower than the photochromic moiety 9 alone, because of the highly efficient FRET processes.

\section{Conclusion}

Through click chemistry, we have successfully introduced three DCM fluorophores and a DAE photochrome on the methyl $\alpha$-Dglucopyranoside in good yield. The multichromophoric compound 2 can be reversibly switched upon UV and visible irradiation, and showed an excellent fatigue resistance. Under UV irradiation at $335 \mathrm{~nm}$, the fluorescence was decreased by $51 \%$. This value corresponds to the photochromic conversion yield at this photostationary state, with $53 \%$ of the DAE molecules promoted to their closed form. We therefore demonstrated that, at the molecular level, one single DAE moiety in the closed form induces the full fluorescence quenching of all three DCM moieties, by a FRET yield close to unity. This study is supported by time-resolved fluorescence experiments. This result represents a step forward, compared to our previous report on the $1 / 1$ system 1 . The increase of the $\mathrm{OF}$ to $\mathrm{CF}$ conversion extent of the photochromic unit is among our future perspectives, since this could lead to a better ON vs OFF fluorescence contrast. By a careful molecular engineering, combining photophysical analysis and synthetic work, we are endeavoring to tune optimally the fluorophore/photochrome ratio. Glycosides, and more generally sugar molecules, may further provide appropriate "platforms".

\section{Experimental \\ General details}

Commercially available solvents and reagents were used without further purification. Compounds 3 [27], 5 [25] and 9 [26] were prepared according to the literature. Melting points were measured on a Kofler bench. Optical rotations were measured using a JASCO P-2000 polarimeter. Column chromatography was performed on Carlo Erba Silica Gel 60A (40-63 $\mu \mathrm{m})$. Analytical thin-layer chromatography was performed on E. Merck aluminum percolated plates of Silica Gel 60F-254 with detection by UV. ${ }^{1} \mathrm{H}$ and ${ }^{13} \mathrm{C}$ NMR spectra were recorded on a Jeol ECS-400 spectrometer. HRMS-ESI spectra were recorded on a Bruker microTOF-Q II spectrometer or Bruker maXis using standard conditions.

Absorption spectra were recorded on a Cary-5000 spectrophotometer from Agilent Technologies. Corrected emission spectra 
were performed on a Fluorolog FL3-221 spectrofluorometer from Horiba Jobin-Yvon. The fluorescence quantum yields were determined by using quinine sulfate dihydrate in sulfuric acid $(0.5 \mathrm{~N})$ as a standard at $\lambda_{\text {exc }}=325 \mathrm{~nm}\left(\Phi_{\mathrm{F}}=0.546\right)$ and coumarin $540 \mathrm{~A}$ in ethanol as a standard at $\lambda_{\text {exc }}=450 \mathrm{~nm}$ $\left(\Phi_{\mathrm{F}}=0.544\right)$. Photochromic reactions were induced in situ by a continuous irradiation $\mathrm{Hg}-\mathrm{Xe}$ lamp (Hamamatsu, LC6 Lightningcure, $200 \mathrm{~W}$ ) equipped with narrow band interference filters of appropriate wavelengths (Semrock FF01-335/7-25 for $\lambda_{\text {irr }}=335 \mathrm{~nm}$; FF01-575/25-25 for $\lambda_{\text {irr }}=575 \mathrm{~nm}$ ). The irradiation power was measured using a photodiode from Ophir (PD300-UV). The photoconversion was followed by a combination of ${ }^{1} \mathrm{H}$ NMR and UV-visible absorption spectra, realized by successive irradiation at $335 \mathrm{~nm}$ for a total time of $20 \mathrm{~min}$. Fluorescence intensity decays were obtained by the time-correlated single-photon counting (TCSPC) method with femtosecond laser excitation using a set-up composed of a Ti:Sa laser (Tsunami, Spectra-Physics) pumped by a doubled Nd:YAG cw-laser (Millennia, Spectra-Physics), pumped itself by two laser diode arrays. Light pulses at $950 \mathrm{~nm}$ were selected by optoacoustic crystals at a repetition rate of $4 \mathrm{MHz}$, and then doubled at $475 \mathrm{~nm}$ by non-linear crystals. Fluorescence photons were detected through a band-pass filter 370-500 nm (a monochromator set at $620 \mathrm{~nm}$, respectively) by means of a Hamamatsu MCP R3809U photomultiplier, connected to a constantfraction discriminator. The time-to-amplitude converter was purchased from Tennelec. In the present investigation, the channel width was set to $3.1 \mathrm{ps}$. The instrumental response function was recorded before each decay measurement with a fwhm (full width at half-maximum) of $\sim 25 \mathrm{ps}$. The fluorescence data were analyzed using the Globals software package developed at the Laboratory for Fluorescence Dynamics at the University of Illinois at Urbana-Champaign, which includes reconvolution analysis and non-linear least-squares minimization method. The shortest fluorescence decay time accessible by our instrumental set-up and our data analysis method was estimated to be around $10 \mathrm{ps}$ (time-resolution).

\section{Methyl 2,3,4-tri-O-propargyl-6-O-trityl-a-D- glucopyranoside (4)}

To a stirred solution of methyl 6- $O$-trityl- $\alpha$-D-glucopyranoside $(3,3.08 \mathrm{~g}, 7.05 \mathrm{mmol})$ in distilled DMF $(60 \mathrm{~mL})$ under argon in an ice bath, were added $\mathrm{Bu}_{4} \mathrm{NI}(3.07 \mathrm{~g}, 8.32 \mathrm{mmol})$ and propargyl bromide $(80 \%$ solution in toluene, $2.3 \mathrm{~mL}$, $20.65 \mathrm{mmol})$. The $\mathrm{NaH}$ (60\% in mineral oil, $1.02 \mathrm{~g}, 25.5 \mathrm{mmol})$ was then added slowly by portions. After $15 \mathrm{~min}$, the mixture was heated at $50{ }^{\circ} \mathrm{C}$ over 2 to $3 \mathrm{~h}$ (brown to black color). After evaporation under vacuum, the residue was partitioned in a mixture of EtOAc/ $\mathrm{H}_{2} \mathrm{O}(200: 200 \mathrm{~mL})$ and the aqueous layer was extracted with EtOAc $(2 \times 100 \mathrm{~mL})$. The organic layers were combined, washed with brine, dried over $\mathrm{MgSO}_{4}$ and evapo- rated under vacuum to give the crude product which was purified by column chromatogrphy using a mixture of petroleum ether (PE):EtOAc $(95: 5,9: 1,8: 2)$ to give $87 \%$ of the desired compound (3.36 g, $6.10 \mathrm{mmol})$ as white solid, mp 96-97 ${ }^{\circ} \mathrm{C}$; $R_{\mathrm{f}}=0.64(\mathrm{PE} / \mathrm{EtOAc}=4: 1) ;[\alpha]_{\mathrm{D}}+51\left(c 0.5, \mathrm{CHCl}_{3}\right) ;{ }^{1} \mathrm{H} \mathrm{NMR}$ $\left(400 \mathrm{MHz}, \mathrm{CDCl}_{3}\right) \delta 2.23(\mathrm{t}, J=2.3 \mathrm{~Hz}, 1 \mathrm{H}, \mathrm{CH} \equiv), 2.45(\mathrm{t}, J=$ $2.3 \mathrm{~Hz}, 1 \mathrm{H}, \mathrm{CH} \equiv), 2.50(\mathrm{t}, J=2.3 \mathrm{~Hz}, 1 \mathrm{H}, \mathrm{CH} \equiv), 3.12(\mathrm{dd}, J=$ 5.0, 10.1 Hz, 1H, H-6), 3.46 (s, 3H, OMe), 3.45-3.49 (m, 1H, H-6'), 3.53 (t, $J=9.2 \mathrm{~Hz}, 1 \mathrm{H}, \mathrm{H}-4), 3.68$ (dd, $J=3.7,9.6 \mathrm{~Hz}$, 1H, H-2), 3.69-3.72 (m, 1H, H-5), 3.78 (t, $J=9.2 \mathrm{~Hz}, 1 \mathrm{H}, \mathrm{H}-3$ ), $4.08(\mathrm{dd}, J=2.8,15.1 \mathrm{~Hz}, 1 \mathrm{H}, \mathrm{OCH}), 4.25(\mathrm{dd}, J=2.8,15.1$ $\mathrm{Hz}, 1 \mathrm{H}, \mathrm{OCH}), 4.40-4.45\left(\mathrm{~m}, 4 \mathrm{H}, 2 \times \mathrm{OCH}_{2}\right), 4.97(\mathrm{~d}$, $J=3.7 \mathrm{~Hz}, 1 \mathrm{H}, \mathrm{H}-1), 7.21-7.32\left(\mathrm{~m}, 9 \mathrm{H}, \mathrm{H}_{\mathrm{Ar}}\right), 7.47-7.49(\mathrm{~m}$, $\left.6 \mathrm{H}, \mathrm{H}_{\mathrm{Ar}}\right) \mathrm{ppm} ;{ }^{13} \mathrm{C} \mathrm{NMR}\left(100 \mathrm{MHz}, \mathrm{CDCl}_{3}\right) \delta 55.05$ (OMe), 58.83, 59.94, $60.59\left(\mathrm{OCH}_{2}\right), 62.83(\mathrm{C}-6), 69.80(\mathrm{C}-5), 74.31$, $75.06\left(\mathrm{C}_{\mathrm{q}}\right), 77.36(\mathrm{C}-4), 79.46(\mathrm{C}-2), 79.87,79.99,80.19$ $(\mathrm{CH} \equiv), 81.75(\mathrm{C}-3), 86.49\left(\mathrm{C}_{\mathrm{q}}\right), 97.79(\mathrm{C}-1), 127.11,127.95$, $128.86\left(\mathrm{CH}_{\mathrm{Ar}}\right), 144.11\left(\mathrm{C}_{\mathrm{q}}\right)$ ppm; HRMS-ESI $(m / z):[\mathrm{M}+\mathrm{Na}]^{+}$ calcd for 573.2253; found: 573.2244 .

\section{DCM-functionalized methyl 6-O-trityl-a-D- glucopyranoside 6}

To a solution of $4(1.01 \mathrm{~g}, 1.83 \mathrm{mmol})$ in distilled DMF $(15 \mathrm{~mL})$, were added the azido-DCM 5 (2.23 g, $5.57 \mathrm{mmol})$, $\mathrm{CuSO}_{4}(110.9 \mathrm{mg}, 0.44 \mathrm{mmol})$ and $\mathrm{Na}$ ascorbate $(188 \mathrm{mg}$, $0.95 \mathrm{mmol})$. The reaction mixture was stirred at $70{ }^{\circ} \mathrm{C}$ during 5 min then at $130{ }^{\circ} \mathrm{C}$ during 30 to 45 min under microwave irradiation (700 rpm, monitoring by TLC), and poured into distilled water after cooling to room temperature. The precipitate was then filtred through a cellulose acetate filter (porosity $2 \mu \mathrm{m}$ ) under vacuum and washed with water, then purified by column chromatography using pure EtOAc, then EtOAc/acetone (gradient 9:1, 8:2, 5:5) then EtOAc/EtOH (7:3) to give $65 \%$ of the desired compound $(2.09 \mathrm{~g}, 1.19 \mathrm{~mol})$ as a red solid; $\mathrm{mp} 164-166{ }^{\circ} \mathrm{C} ; R_{\mathrm{f}}=0.29($ EtOAc/acetone $=9: 1) ;[\alpha]_{\mathrm{D}}$ $+12\left(c \quad 0.5, \mathrm{CHCl}_{3}\right) ;{ }^{1} \mathrm{H}$ NMR (400 MHz, acetone- $\left.d_{6}\right) \delta 1.38(\mathrm{~s}$, $\left.27 \mathrm{H}, \mathrm{H}_{t-\mathrm{Bu}}\right), 2.84$ (s, 3H, NMe), $2.85(\mathrm{~s}, 3 \mathrm{H}, \mathrm{NMe}), 2.85(\mathrm{~s}, 3 \mathrm{H}$, NMe), 3.10 (dd, $J=4.6,10.1 \mathrm{~Hz}, 1 \mathrm{H}, \mathrm{H}-6), 3.39-3.40$ (m, 1H, H-6'), 3.41 (s, 3H, OMe), 3.50 (t, $J=9.5 \mathrm{~Hz}, 1 \mathrm{H}, \mathrm{OCH}), 3.55$ $(\mathrm{dd}, J=3.7,9.6 \mathrm{~Hz}, \mathrm{H}-2), 3.62-3.70(\mathrm{~m}, 2 \mathrm{H}, 2 \times \mathrm{OCH})$, $3.82-3.99\left(\mathrm{~m}, 6 \mathrm{H}, 3 \times \mathrm{NCH}_{2}\right), 4.34(\mathrm{~d}, J=11.4 \mathrm{~Hz}, 1 \mathrm{H}, \mathrm{NCH})$, $4.58-4.86\left(\mathrm{~m}, 11 \mathrm{H}, \mathrm{NCH}, 2 \times \mathrm{NCH}_{2}, 3 \times \mathrm{OCH}_{2}\right), 4.98(\mathrm{~d}$, $J=3.7 \mathrm{~Hz}, 1 \mathrm{H}, \mathrm{H}-1), 6.45-6.46(\mathrm{~m}, 3 \mathrm{H}, 3 \times \mathrm{CH}=), 6.56-6.73$ $(\mathrm{m}, 9 \mathrm{H}, 9 \times \mathrm{CH}=), 6.81(\mathrm{~d}, J=16.0 \mathrm{~Hz}, 1 \mathrm{H}, \mathrm{CH}=), 6.86(\mathrm{~d}$, $J=16.0 \mathrm{~Hz}, 1 \mathrm{H}, \mathrm{CH}=), 6.87(\mathrm{~d}, J=16.0 \mathrm{~Hz}, 1 \mathrm{H}, \mathrm{CH}=)$, 7.21-7.33 (m, 10H, 10×CH=), $7.39\left(\mathrm{~s}, 1 \mathrm{H}, \mathrm{H}_{\text {Triazole }}\right), 7.41-7.53$ $(\mathrm{m}, 14 \mathrm{H}, 14 \times \mathrm{CH}=), 8.15\left(\mathrm{~s}, 1 \mathrm{H}, \mathrm{H}_{\text {Triazole }}\right), 8.17(\mathrm{~s}, 1 \mathrm{H}$, $\left.\mathrm{H}_{\text {Triazole }}\right) \mathrm{ppm} ;{ }^{13} \mathrm{C} \mathrm{NMR}\left(100 \mathrm{MHz}\right.$, acetone- $\left.d_{6}\right) \delta 28.14$ $\left(\mathrm{Me}_{t-\mathrm{Bu}}\right), 37.26\left(\mathrm{C}_{\mathrm{q}}\right), 38.63,38.78(\mathrm{NMe}), 47.99,48.12,48.18$, $52.89\left(\mathrm{NCH}_{2}\right), 55.14(\mathrm{OMe}), 57.61\left(\mathrm{C}_{\mathrm{q}}\right), 63.50(\mathrm{C}-6), 64.41$, 66.39, $66.98\left(\mathrm{OCH}_{2}\right), 69.68\left(\mathrm{C}_{\mathrm{q}}\right), 70.96(\mathrm{C}-5), 78.46,80.40$, 
$81.91(\mathrm{C}-2,3,4), 87.03\left(\mathrm{C}_{\mathrm{q}}\right), 98.37(\mathrm{C}-1), 102.62,106.02$, 106.07, 112.67, 112.75, 114.21, $114.33(\mathrm{CH}=), 116.13,116.18$, 123.98, $124.07\left(\mathrm{C}_{\mathrm{q}}\right), 124.81,125.29,125.45\left(\mathrm{CH}_{\text {Triazole }}\right)$, $127.86,128.66,129.56,130.79,130.84,139.11,139.22(\mathrm{CH}=)$, $145.00,145.56,145.91,146.14,151.13,151.18,157.49,157.49$, 161.50, 161.55, $173.02\left(\mathrm{C}_{\mathrm{q}}\right)$ ppm; HRMS-ESI $(\mathrm{m} / \mathrm{z}):[\mathrm{M}+\mathrm{H}]^{+}$ calcd for 1751.8463; found: 1751.8397 .

\section{DCM-functionalized methyl a-D-glucopyrano- side 7}

To a stirred solution of compound $6(940 \mathrm{mg}, 0.54 \mathrm{mmol})$ in a mixture of $\mathrm{CH}_{2} \mathrm{Cl}_{2} / \mathrm{MeOH}(10 / 10 \mathrm{~mL})$ cooled in an ice bath, was added acetyl chloride ( $115 \mu \mathrm{L}, 1.61 \mathrm{mmol})$. After $2.5 \mathrm{~h}$, the reaction was quenched by addition of a saturated $\mathrm{NaHCO}_{3}$ solution $(5 \mathrm{~mL})$. The mixture was extracted with $\mathrm{CH}_{2} \mathrm{Cl}_{2}$. The organic layers were combined, washed with brine, dried over $\mathrm{MgSO}_{4}$ and evaporated under vacuum. The product was purified by column chromatography using pure EtOAc followed by a mixture of EtOAc/acetone (gradient 9:1, 8:2, 7:3, 6:4) to give $74 \%$ of the desired compound $(600 \mathrm{mg}, 0.40 \mathrm{mmol})$ as a red solid; $\mathrm{mp} 156-158{ }^{\circ} \mathrm{C} ; R_{\mathrm{f}}=0.22($ EtOAc/acetone $=4: 1) ;[\alpha]_{\mathrm{D}}$ $+25\left(c \quad 0.5, \mathrm{CHCl}_{3}\right) ;{ }^{1} \mathrm{H} \mathrm{NMR}\left(400 \mathrm{MHz}, \mathrm{CDCl}_{3}\right) \delta 1.37(\mathrm{~s}$, $\left.27 \mathrm{H}, \mathrm{H}_{t-\mathrm{Bu}}\right), 2.89$ (s, 3H, NMe), 2.91 (s, 3H, NMe), 2.92 (s, 3H, $\mathrm{NMe}$ ), 3.37 (s, 3H, OMe), 3.47 (dd, $J=3.2,9.6 \mathrm{~Hz}, 1 \mathrm{H}, \mathrm{H}-2)$, 3.52-3.54 (m, 2H, H-3,4), 3.73 (s, 2H, H-6,6'), 3.80-3.83 (m, $1 \mathrm{H}, \mathrm{H}-5), 3.92-3.94\left(\mathrm{~m}, 6 \mathrm{H}, 3 \times \mathrm{NCH}_{2}\right), 4.58-4.60(\mathrm{~m}, 6 \mathrm{H}$, $\left.3 \times \mathrm{NCH}_{2}\right), 4.74-4.97\left(\mathrm{~m}, 7 \mathrm{H}, \mathrm{H}-1,3 \times \mathrm{OCH}_{2}\right), 6.45-6.65(\mathrm{~m}$, $16 \mathrm{H}, 16 \times \mathrm{CH}=), 7.25-7.42(\mathrm{~m}, 8 \mathrm{H}, 8 \times \mathrm{CH}=), 7.63(\mathrm{~s}, 1 \mathrm{H}$, $\left.\mathrm{H}_{\text {Triazole }}\right), 7.87$ (s, 1H, $\left.\mathrm{H}_{\text {Triazole }}\right), 8.00$ (s, $\left.1 \mathrm{H}, \mathrm{H}_{\text {Triazole }}\right) \mathrm{ppm}$; ${ }^{13} \mathrm{C}$ NMR $\left(100 \mathrm{MHz}, \mathrm{CDCl}_{3}\right) \delta 28.18\left(\mathrm{Me}_{t-\mathrm{Bu}}\right), 36.70\left(\mathrm{C}_{\mathrm{q}}\right)$, 38.59, 38.66, $38.74(\mathrm{NMe}), 47.49,47.57,52.53\left(\mathrm{NCH}_{2}\right), 55.22$ $(\mathrm{OMe}), 57.89,57.94\left(\mathrm{C}_{\mathrm{q}}\right), 61.18(\mathrm{C}-6), 64.13,65.75,66.27$ $\left(\mathrm{OCH}_{2}\right), 69.60\left(\mathrm{C}_{\mathrm{q}}\right), 70.71,77.36(\mathrm{C}-3,4), 79.39(\mathrm{C}-2), 81.42$ (C-5), 97.51 (C-1), 102.43, 105.81, 111.98, 112.03, 113.81 $(\mathrm{CH}=), 115.70,115.81,115.86,123.30,123.35,123.41\left(\mathrm{C}_{\mathrm{q}}\right)$, 123.86, 124.43, 124.74 ( $\left.\mathrm{CH}_{\text {Triazole }}\right), 129.91,137.95,138.02$ $(\mathrm{CH}=), 144.90,145.32,145.42,149.84,149.92,149.98,156.83$, $160.01,160.01,160.05,172.04\left(\mathrm{C}_{\mathrm{q}}\right)$ ppm. HRMS-ESI $(\mathrm{m} / \mathrm{z})$ : $[\mathrm{M}+\mathrm{H}]^{+}$calcd for 1509.7367 ; found: $1509.7332 ;[\mathrm{M}+2 \mathrm{H}]^{2+}$ calcd for 755.3720; found: 755.3715 .

\section{DCM-functionalized methyl 6-azido-6-deoxy- a-D-glucopyranoside 8}

To a stirred solution of compound 7 (414 $\mathrm{mg}, 0.27 \mathrm{mmol})$ in $\mathrm{CH}_{2} \mathrm{Cl}_{2}(2 \mathrm{~mL})$ were added $\mathrm{Et}_{3} \mathrm{~N}(125 \mu \mathrm{L}, 0.90 \mathrm{mmol})$ and $\mathrm{MsCl}(52 \mu \mathrm{L}, 0.67 \mathrm{mmol})$. After stirring $3.5 \mathrm{~h}$, the mixture was treated with $10 \mathrm{~mL}$ of water and the aqueous layer was extracted with $\mathrm{CH}_{2} \mathrm{Cl}_{2}(3 \times 20 \mathrm{~mL})$. The organic layers were combined, washed with brine, dried over $\mathrm{MgSO}_{4}$ and evaporated under vacuum to a crude mesylate which was used without purification for the next step. To a solution of crude mesylate in DMF (3 $\mathrm{mL})$ was added sodium azide $(29.9 \mathrm{mg}$, $0.46 \mathrm{mmol}$ ) and the mixture was stirred at $110^{\circ} \mathrm{C}$ during $15 \mathrm{~min}$ under microwave irradiation (700 rpm, monitoring by TLC). After cooling to room temperature, the reaction mixture was poured into 20 to $25 \mathrm{~mL}$ of distilled water. The precipitate was then filtred through cellulose acetate filter (porosity $2 \mu \mathrm{m}$ ) under vacuum and washed with water. The product was purified by column chromatography using EtOAc/acetone (gradient $1: 0$ to $9: 1$ ) to give $75 \%$ of the desired compound (328 mg, $0.21 \mathrm{mmol})$ as a red solid; $\mathrm{mp} 156-158{ }^{\circ} \mathrm{C} ; R_{\mathrm{f}}=0.49$ $($ EtOAc/acetone $=4: 1) ;[\alpha]_{\mathrm{D}}+9\left(c 0.5, \mathrm{CHCl}_{3}\right) ;{ }^{1} \mathrm{H} \mathrm{NMR}$ $\left(400 \mathrm{MHz} \mathrm{CDCl}_{3}\right) \delta 1.37\left(\mathrm{~s}, 27 \mathrm{H}, \mathrm{H}_{t-\mathrm{Bu}}\right), 2.91(\mathrm{~s}, 3 \mathrm{H}, \mathrm{NMe})$, $2.92(\mathrm{~s}, 3 \mathrm{H}, \mathrm{NMe}), 2.92$ (s, 3H, NMe), 3.31-3.51 (m, 3H, H-4,6,6'), 3.39 (s, 3H, OMe), 3.49 (dd, $J=3.7,9.6 \mathrm{~Hz}, 1 \mathrm{H}$, H-2), 3.64-3.69 (m, 1H, H-5), 3.79 (t, $J=9.6 \mathrm{~Hz}, 1 \mathrm{H}, \mathrm{H}-3)$, $3.90-3.97\left(\mathrm{~m}, 6 \mathrm{H}, 3 \times \mathrm{NCH}_{2}\right), 4.57-4.64\left(\mathrm{~m}, 6 \mathrm{H}, 3 \times \mathrm{NCH}_{2}\right)$, 4.65-4.97 (m, 7H, $\left.3 \times \mathrm{OCH}_{2}, \mathrm{H}-1\right), 6.46-6.66(\mathrm{~m}, 16 \mathrm{H}$, $16 \times \mathrm{CH}=), 7.26-7.42(\mathrm{~m}, 8 \mathrm{H}, 8 \times \mathrm{CH}=), 7.69\left(\mathrm{~s}, 1 \mathrm{H}, \mathrm{H}_{\text {Triazole }}\right)$, 7.89 (s, $\left.1 \mathrm{H}, \mathrm{H}_{\text {Triazole }}\right), 8.00\left(\mathrm{~s}, 1 \mathrm{H}, \mathrm{H}_{\text {Triazole }}\right) \mathrm{ppm} ;{ }^{13} \mathrm{C} \mathrm{NMR}$ $\left(100 \mathrm{MHz}, \mathrm{CDCl}_{3}\right) \delta 28.16\left(\mathrm{Me}_{t-\mathrm{Bu}}\right), 36.68\left(\mathrm{C}_{\mathrm{q}}\right), 38.54,38.65$, $38.71(\mathrm{NMe}), 47.51\left(\mathrm{NCH}_{2}\right), 51.22(\mathrm{C}-6), 52.52\left(\mathrm{NCH}_{2}\right), 55.39$ $(\mathrm{OMe}), 57.84,57.91,57.91\left(\mathrm{C}_{\mathrm{q}}\right), 64.26,65.87,66.28\left(\mathrm{OCH}_{2}\right)$, $69.57\left(\mathrm{C}_{\mathrm{q}}\right), 69.83(\mathrm{C}-5), 77.37\left(\mathrm{C}_{\mathrm{q}}\right), 78.00(\mathrm{C}-4), 79.29(\mathrm{C}-2)$, 81.08 (C-3), 97.43 (C-1), 102.41, 105.80, 111.95, 112.01, 113.73, $113.78(\mathrm{CH}=), 115.70,115.83,123.31,123.37\left(\mathrm{C}_{\mathrm{q}}\right)$, 124.13, 124.43, $124.77\left(\mathrm{CH}_{\text {Triazole }}\right), 129.89\left(\mathrm{C}_{\mathrm{q}}\right), 137.89$, 137.93, $138.02(\mathrm{CH}=), 144.81,144.86,145.27,149.86,149.96$, 149.96, 156.80, 159.97, 160.03, $172.02\left(\mathrm{C}_{\mathrm{q}}\right)$ ppm; HRMS-ESI $(\mathrm{m} / \mathrm{z}):[\mathrm{M}+\mathrm{H}]^{+}$calcd for 1534.7432 ; found: 1534.7381 ; $[\mathrm{M}+$ $2 \mathrm{H}]^{2+}$ calcd for 767.8753 ; found: 767.8746 .

\section{DCM and DAE-functionalized methyl $\alpha-D-$ glucopyranoside 2}

To a solution of compound 8 (51.1 $\mathrm{mg}, 0.033 \mathrm{mmol})$ in DMF $(2 \mathrm{~mL})$ were added the photochromic compound 9 (62.0 $\mathrm{mg}$, $0.111 \mathrm{mmol}), \mathrm{CuSO}_{4}(2.5 \mathrm{mg}, 0.010 \mathrm{mmol})$ and $\mathrm{Na}$ ascorbate $(6.8 \mathrm{mg}, 0.034 \mathrm{mmol})$. The reaction mixture was stirred at $70{ }^{\circ} \mathrm{C}$ during $5 \mathrm{~min}$ then at $130{ }^{\circ} \mathrm{C}$ during 30 to $45 \mathrm{~min}$ under microwave irradiation ( $700 \mathrm{rpm}$, monitoring by TLC), and poured into distilled water after cooling to room temperature. The precipitate was then filtred through a cellulose acetate filter (porosity $2 \mu \mathrm{m}$ ) under vacuum and washed with water, then purified by column chromatogrphy using EtOAc:ethanol (9:1) to give $66 \%$ of the desired compound $(45.8 \mathrm{mg}, 0.022 \mathrm{mmol}$ ) as a red solid; $\mathrm{mp} 181-183{ }^{\circ} \mathrm{C} ; R_{\mathrm{f}}=0.53($ EtOAc/acetone $=4: 1)$; $[\alpha]_{\mathrm{D}}+45\left(c 0.5, \mathrm{CHCl}_{3}\right) ;{ }^{1} \mathrm{H} \mathrm{NMR}\left(400 \mathrm{MHz}, \mathrm{CDCl}_{3}\right) \delta 1.36(\mathrm{~s}$, $\left.27 \mathrm{H}, \mathrm{H}_{t-\mathrm{Bu}}\right), 2.09$ (s, 3H, Me), $2.54(\mathrm{~s}, 3 \mathrm{H}, \mathrm{Me}), 2.88(\mathrm{~s}, 3 \mathrm{H}$, $\mathrm{NMe}), 2.90(\mathrm{~s}, 3 \mathrm{H}, \mathrm{NMe}), 2.92(\mathrm{~s}, 3 \mathrm{H}, \mathrm{NMe}), 2.97$ (t, $J=9.6 \mathrm{~Hz}, 1 \mathrm{H}, \mathrm{H}-4), 3.21$ (s, 3H, OMe), 3.35 (dd, $J=3.2$, $9.6 \mathrm{~Hz}, 1 \mathrm{H}, \mathrm{H}-2), 3.79-3.93\left(\mathrm{~m}, 8 \mathrm{H}, \mathrm{H}-3,5,3 \times \mathrm{NCH}_{2}\right)$, 4.45-4.81 (m, 13H, H-1,6,6', $\left.3 \times \mathrm{NCH}_{2}, 2 \times \mathrm{OCH}_{2}\right), 4.93$ (d, 
$J=11.4 \mathrm{~Hz}, 1 \mathrm{H}, \mathrm{OCH}), 4.97(\mathrm{~d}, J=11.5 \mathrm{~Hz}, 1 \mathrm{H}, \mathrm{OCH}), 5.26$ $\left(\mathrm{s}, 2 \mathrm{H}, \mathrm{OCH}_{2}\right), 6.45-6.64(\mathrm{~m}, 15 \mathrm{H}, 15 \times \mathrm{CH}=), 7.02(\mathrm{~d}$, $J=8.7 \mathrm{~Hz}, 2 \mathrm{H}, 2 \times \mathrm{CH}=), 7.26-7.49(\mathrm{~m}, 15 \mathrm{H}, 15 \times \mathrm{CH}=)$, $7.77-7.79(\mathrm{~m}, 4 \mathrm{H}, 4 \times \mathrm{CH}=), 7.88(\mathrm{~d}, 2 \mathrm{H}, J=8.7 \mathrm{~Hz}, 2 \times \mathrm{CH}=)$, $7.97\left(\mathrm{~s}, 1 \mathrm{H}, \mathrm{H}_{\text {Triazole }}\right), 8.03-8.09(\mathrm{~m}, 3 \mathrm{H}, 3 \times \mathrm{CH}=) \mathrm{ppm}$; ${ }^{13} \mathrm{C}$ NMR $\left(100 \mathrm{MHz}, \mathrm{CDCl}_{3}\right) \delta 12.46,12.94(\mathrm{Me}), 28.25$ $\left(\mathrm{Me}_{t-\mathrm{Bu}}\right), 36.77\left(\mathrm{C}_{\mathrm{q}}\right), 38.79,38.88(\mathrm{NMe}), 47.56,47.68$ $\left(\mathrm{NCH}_{2}\right), 50.54(\mathrm{C}-6), 52.56,52.62,52.72\left(\mathrm{NCH}_{2}\right), 55.56$ $(\mathrm{OMe}), 58.20,58.28\left(\mathrm{C}_{\mathrm{q}}\right), 62.07,64.23,65.96,66.27\left(\mathrm{OCH}_{2}\right)$, $68.89(\mathrm{CH}), 69.65\left(\mathrm{C}_{\mathrm{q}}\right), 77.36,79.31,81.05(\mathrm{OCH}), 97.56$ (C-1), 102.54, 112.21, 113.95, 114.05, 114.09, $115.29(\mathrm{CH}=)$, $115.71,115.87,123.51,123.55,123.60,123.66\left(\mathrm{C}_{\mathrm{q}}\right), 124.57$, 124.68, 124.94, 126.41, 126.72, 128.20, 128.89, 129.08, 129.95, $130.40(\mathrm{CH}=), 133.59,133.68\left(\mathrm{C}_{\mathrm{q}}\right), 137.89,137.95,138.02$ $(\mathrm{CH}=), 143.90,144.78,144.99,145.06,149.85,156.89,160.02$, 163.93, 164.13, 167.30, $172.08\left(\mathrm{C}_{\mathrm{q}}\right)$ ppm; HRMS-ESI $(\mathrm{m} / \mathrm{z})$ : $[\mathrm{M}+2 \mathrm{H}]^{2+}$ calcd for 1048.4254 ; found: $1048.4247 ;[\mathrm{M}+$ $3 \mathrm{H}]^{3+}$ calcd for 699.2860 ; found: 699.2845 .

\section{References}

1. Irie, M., Ed. Photochromism: Memories and Switches. Chem. Rev. 2000, 100, 1683-1890. doi:10.1021/cr980068I

2. Fukaminato, T. J. Photochem. Photobiol., C 2011, 12, 177-208. doi:10.1016/j.jphotochemrev.2011.08.006

3. Guo, Z.; Zhu, W.; Tian, H. Chem. Commun. 2012, 48, 6073-6084. doi:10.1039/c2cc31581e

4. Ouhenia-Ouadahi, K.; Métivier, R.; Maisonneuve, S.; Jacquart, A.; Xie, J.; Léaustic, A.; Yu, P.; Nakatani, K. Photochem. Photobiol. Sci. 2012, 11, 1705-1714. doi:10.1039/c2pp25129a

5. Bossi, M.; Belov, V.; Polyakova, S.; Hell, S. W. Angew. Chem., Int. Ed. 2006, 45, 7462-7465. doi:10.1002/anie.200602591

6. Berberich, M.; Krause, A.-M.; Orlandi, M.; Scandola, F.; Würthner, F. Angew. Chem., Int. Ed. 2008, 47, 6616-6619. doi:10.1002/anie.200802007

7. Irie, M.; Fukaminato, T.; Sasaki, T.; Tamai, N.; Kawai, T. Nature 2002, 420, 759-760. doi:10.1038/420759a

8. Jiang, G.; Wang, S.; Yan, W.; Jiang, L.; Song, Y.; Tian, H.; Zhu, D. Chem. Mater. 2006, 18, 235-237. doi:10.1021/cm052251i

9. Golovkova, T. A.; Kozlov, D. V.; Neckers, D. C. J. Org. Chem. 2005, 70, 5545-5549. doi:10.1021/jo050540k

10. Wu, S.; Luo, Y.; Zeng, F.; Chen, J.; Chen, Y.; Tong, Z. Angew. Chem., Int. Ed. 2007, 46, 7015-7018. doi:10.1002/anie.200701396

11. Del Guerzo, A.; Olive, A. G. L.; Reichwagen, J.; Hopf, H.; Desvergne, J.-P. J. Am. Chem. Soc. 2005, 127, 17984-17985. doi:10.1021/ja0566228

12. Fölling, J.; Polyakova, S.; Belov, V.; van Blaaderen, A.; Bossi, M. L.; Hell, S. W. Small 2008, 4, 134-142. doi:10.1002/smll.200700440

13. Métivier, R.; Badré, S.; Méallet-Renault, R.; Yu, P.; Pansu, R. B.; Nakatani, K. J. Phys. Chem. C 2009, 113, 11916-11926. doi:10.1021/jp902344x

14. Wu, Y.; Xie, Y.; Zhang, Q.; Tian, H.; Zhu, W.; Li, A. D. Q. Angew. Chem., Int. Ed. 2014, 53, 2090-2094. doi:10.1002/anie.201309915
15. Nakashima, T.; Kajiki, Y.; Fukumoto, S.; Taguchi, M.; Nagao, S.; Hirota, S.; Kawai, T. J. Am. Chem. Soc. 2012, 134, 19877-19883. doi:10.1021/ja309275q

16. Snegir, S. V.; Marchenko, A. A.; Yu, P.; Maurel, F.; Kapitanchuk, O. L.; Mazerat, S.; Lepeltier, M.; Léaustic, A.; Lacaze, E. J. Phys. Chem. Lett. 2011, 2, 2433-2436. doi:10.1021/jz200875c

17. Bonaccorsi, P.; Aversa, M. C.; Barattucci, A.; Papalia, T.; Puntoriero, F.; Campagna, S. Chem. Commun. 2012, 48, 10550-10552. doi:10.1039/c2cc35555h

18. Kolb, H. C.; Finn, M. G.; Sharpless, K. B. Angew. Chem., Int. Ed. 2001, 40, 2004-2021.

doi:10.1002/1521-3773(20010601)40:11<2004::AID-ANIE2004>3.0.CO ;2-5

19. Tornøe, C. W.; Christensen, C.; Meldal, M. J. Org. Chem. 2002, 67, 3057-3064. doi:10.1021/jo011148j

20. Wu, P.; Feldman, A. K.; Nugent, A. K.; Hawker, C. J.; Scheel, A.; Voit, B.; Pyun, J.; Fréchet, J. M. J.; Sharpless, K. B.; Fokin, V. V. Angew. Chem., Int. Ed. 2004, 43, 3928-3932. doi:10.1002/anie.200454078

21. Wu, P.; Chen, X.; Hu, N.; Tam, U. C.; Blixt, O.; Zettl, A.; Bertozzi, C. R. Angew. Chem., Int. Ed. 2008, 47, 5022-5025. doi:10.1002/anie.200705363

22. Gao, Y.; Eguchi, A.; Kakehi, K.; Lee, Y. C. Bioorg. Med. Chem. 2005, 13, 6151-6157. doi:10.1016/j.bmc.2005.06.036

23. Perez-Balderas, F.; Morales-Sanfrutos, J.; Hernandez-Mateo, F.; Isac-García, J.; Santoyo-Gonzalez, F. Eur. J. Org. Chem. 2009, 2441-2453. doi:10.1002/ejoc.200801170

24. Ortega-Muñoz, M.; Perez-Balderas, F.; Morales-Sanfrutos, J.; Hernandez-Mateo, F.; Isac-García, J.; Santoyo-Gonzalez, F. Eur. J. Org. Chem. 2009, 2454-2473. doi:10.1002/ejoc.200801169

25. Yu, Y.; Bogliotti, N.; Maisonneuve, S.; Tang, J.; Xie, J. Tetrahedron Lett. 2013, 54, 1877-1883. doi:10.1016/j.tetlet.2013.01.119

26. Ouhenia-Ouadahi, K.; Yasukuni, R.; Yu, P.; Laurent, G.; Pavageau, C.; Grand, J.; Guérin, J.; Léaustic, A.; Félidj, N.; Aubard, J.; Nakatani, K.; Métivier, R. Chem. Commun. 2014, 50, 7299-7302. doi:10.1039/c4cc02179g

27. Collins, D. J.; Hibberd, A. I.; Skelton, B. W.; White, A. H. Aust. J. Chem. 1998, 51, 681-694. doi:10.1071/C97156

\section{License and Terms}

This is an Open Access article under the terms of the Creative Commons Attribution License (http://creativecommons.org/licenses/by/2.0), which permits unrestricted use, distribution, and reproduction in any medium, provided the original work is properly cited.

The license is subject to the Beilstein Journal of Organic Chemistry terms and conditions: (http://www.beilstein-journals.org/bjoc)

The definitive version of this article is the electronic one which can be found at: $\underline{\text { doi:10.3762/bjoc. } 10.151}$ 